lazana Matuella

Universidade Federal de Pelotas, Pelotas, RS, Brasil

\title{
Conflitos armados e a agenda internacional: a questão da mulher
}

Resumo: A violência contra a mulher é um debate antigo e possui reivindicações de mulheres, de forma organizada, há mais de um século. Porém, sua introdução como importante tema na agenda internacional foi recente e dependeu de um grande esforço de grupos de mulheres. Assim, esse artigo pretende analisar como os movimentos de mulheres, desde 1945, com a criação da Organização das Nações Unidas, influenciaram a incorporação da problemática da violência contra a mulher, principalmente em períodos de conflitos armados, pelo sistema internacional de proteção da pessoa humana, bem como a observância dessas diretrizes pelos Estados e Organizações Internacionais. O argumento aqui apresentado é que apenas a partir da década de 1990, com as Transnational Advocacy Networks (TANs) efetivadas e pela consideração dos Direitos das Mulheres como um Direito Humano fundamental, foi que a temática recebeu a valoração que merecia na agenda internacional. Esse impacto escoou também para o âmbito dos conflitos armados, onde as mulheres são as mais impactadas e vulnerabilizadas. Portanto, diversas normas foram criadas a fim de eliminar a violência de gênero, e conclui-se que a principal falha se mantém na inobservância dessas diretrizes, tanto a nível estatal como internacional.

Palavras-chave: violência contra a mulher; feminismo; direitos humanos; conflitos armados

\section{Introdução}

A questão da violência contra a mulher é tão antiga quanto a história humana e foi por muito tempo ignorada pela sociedade, políticos e estudiosos. A persistência da violência contra a mulher como um tema que ultrapassa as barreiras do doméstico e do privado, estando presente no meio internacional e especialmente durante conflitos armados, traz relevância para que estudos nessa temática sejam incentivados.

Os desafios são muitos ao tratar sobre essa questão, desde um preconceito disciplinar, constatado também na área de Relações Internacionais (RI), tendo sido uma das últimas

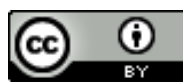

Esta obra está sob licença Creative Commons. 
áreas das Ciências Sociais a ter o debate de gênero, bem como no âmbito social e político, devido a uma cultura masculinizada que é refletida em nossas instituições e normas.

O movimento feminista foi reconhecido de forma organizada a partir do final do século XIX, com a luta pelo sufrágio, principalmente nos países europeus e nos Estados Unidos. Após isso, transcorreram por outros períodos as chamadas Ondas do Feminismo, onde se aprimoraram estudos, organizações e reivindicações.

Impulsionado por essas razões, este artigo busca compreender como os movimentos de mulheres influenciaram a incorporação da problemática da violência contra a mulher, principalmente em períodos de conflitos armados, pelo sistema internacional de proteção da pessoa humana. Será delimitado um período de estudo a partir da criação da Organização das Nações Unidas (ONU), em 1945, levando em consideração a influência dessa Organização nos Estados e na sociedade mundial, bem como a coordenação das mulheres em volta dessa instituição capaz de internacionalizar suas demandas.

Será utilizado o conceito de Transnational Advocacy Networks (TANs), pela sua capacidade de descrever a heterogeneidade de grupos de mulheres organizados transnacionalmente e articulados internacionalmente. O termo, cunhado por Margaret $\mathrm{E}$. KECK e Kathryn SIKKINK (1999), expressa uma "forma de organização baseada em padrões de comunicação e trocas voluntárias, recíprocas e horizontais" (p. 91) e designa a formação de redes capazes de se comunicarem e se organizarem por objetivos comuns. Devido às diferentes reivindicações dos movimentos feministas e de mulheres do Norte ao Sul global, os diálogos desenvolvidos através de tais redes buscam constituir uma agenda que seja globalmente representativa e exerça influência e pressão sobre diversos atores do sistema internacional, principalmente ONU e Estados nacionais. O artigo pretende demonstrar de que forma a incorporação dos direitos das mulheres como um direito humano fundamental a partir das conferências internacionais ao longo da década de 1990 possibilitou que a problemática da violência contra a mulher fosse colocada definitivamente na agenda internacional, abrindo espaço para a elaboração e denúncia de algumas de suas especificidades, tais como aquelas envolvidas em situações de conflitos armados - muito característicos, inclusive, dos anos noventa. Nesse contexto, a atuação das TANs foi fundamental.

Dessa forma, este artigo realizou uma pesquisa exploratória e qualitativa, buscando descrever características de um fenômeno, interpretando-o e atribuindo-lhe significados. Utilizando técnicas de pesquisa documental, em documentos oficiais de fontes secundárias, tais como conferências, convenções e resoluções, e, também, de artigos de estudiosos/as sobre o tema, averiguou-se sobre como se deu o desenvolvimento da mobilização transnacional de mulheres e seu impacto nas diretrizes institucionais e políticas, seguidas por Estados e Organizações Internacionais.

Para isso, primeiramente, a partir de uma análise teórica conceitual, será compreendida a abordagem feminista nas Relações Internacionais, no âmbito do terceiro debate teórico das RI, incorporando o poder de gênero como um nível de análise. Na seção seguinte, analisar-se-á o desenvolvimento normativo/jurídico dos direitos das mulheres, principalmente a partir da década de 1970, com a criação dos primeiros instrumentos internacionais versando sobre a temática da violência contra a mulher, emitindo recomendações para Estados e sociedade em geral.

Em sua última parte, esse artigo versará sobre a questão da violência contra a mulher, em particular nos conflitos armados, analisando se a incorporação da temática na agenda e os esforços de TANs de mulheres impactaram sua atenção também nesse âmbito. Nesta seção também serão explorados os desafios e as dificuldades enfrentadas para a 
consolidação dos direitos das mulheres na esfera internacional, refletindo em uma observância tanto no plano doméstico, internacional, como também em situações extremas de conflitos armados.

\section{- feminismo nas relações internacionais: alguns apontamentos teóricos}

A principal preocupação para a teoria feminista é explicar a subordinação das mulheres e a assimetria entre homens e mulheres nas posições sociais, econômicas e políticas, e, assim, encontrar soluções para essa problemática. Susan Okin (1999 apud Ann J. TICKNER, 2001) define como feministas as pessoas que acreditam que as mulheres "não devem ter desvantagens por causa do seu sexo, ou seja, mulheres devem ter sua dignidade humana reconhecida de forma igual aos homens e a oportunidade de viverem, igualmente, livres" (p. 11).

A organização de grupos de mulheres no final do século XIX e início do século XX foi considerada como constitutiva da primeira onda do feminismo, e tinha como principal objetivo as reivindicações pelos direitos civis em resposta à exclusão das mulheres na política. Nomeado como "Sufragismo", o movimento teve suas bases principalmente na Inglaterra, militou para o direito do voto às mulheres e estava fortemente conectado aos interesses de mulheres brancas e europeias. Segundo Keck e Sikkink (1998 apud Elisabeth Jay FRIEDMAN, 2003), o movimento do sufrágio foi reforçado pelas reuniões internacionais e as comunicações entre ativistas ajudaram a propagação de ideias.

Durante a segunda onda feminista, que foi da década de 1960 a 1990, diversas mulheres ativistas presentes em outros grupos de libertação - nacionalistas, comunistas, anarquistas - perceberam estar subordinadas a homens também dentro dessas atividades. Assim, muitas se deslocaram para grupos específicos para a libertação das mulheres ou lutaram para colocar a demanda da desigualdade de gênero dentro de outras lutas. Mesmo não tendo uma ligação transnacional direta, esses novos grupos formados foram de extrema importância para uma futura interação entre fronteiras.

No âmbito disciplinar, apesar da associação de características supostamente masculinas como força, autonomia, independência e racionalidade com a política internacional, o campo das Relações Internacionais foi uma das últimas Ciências Sociais a ter o debate de análise de gênero. Tickner (1992) explica que a razão para isso não seria, como muitos afirmam, que o campo das RI é neutro, sendo que a perspectiva de gênero seria irrelevante, mas, sim, que essa área é tão masculinizada que os trabalhos sobre as relações de gênero estariam escondidos.

A aproximação dos Estudos de Gênero com as Relações Internacionais só se deu no âmbito do terceiro debate teórico, posterior à abertura paradigmática das RI no final dos anos 1980, criando espaço para contestações teóricas e epistemológicas:

Foi durante a desestabilizadora década de 1980 que feministas, o maior foco de consideração aqui, começaram jornadas individuais e coletivas de autoconhecimento, pesquisa compensatória e ascendência de seu reconhecimento por parte dos detentores históricos das RI (Christine SYLVESTER, 2002, p. 8 [tradução livre]).

Assim, a dicotomia entre Realismo e Liberalismo, mesmo em suas versões mais contemporâneas, começou a ter sua hegemonia explicativa e normativa questionada. $O$ chamado debate pós-positivista das RI incitou diferentes conceitos, olhares e perspectivas de análise. Novas abordagens para a área, tais como o construtivismo, o pós-estruturalismo, o pós-colonialismo, o feminismo, a green theory, entre outras, apresentavam novas formas 
de análise e contestavam o conhecimento tradicional, levando em conta a falta de "um legado de inclusão e justiça" (SYLVESTER, 2002. p. 6).

Com o fim da Guerra Fria houve uma maior preocupação com abordagens que explicassem a "construção social da política mundial", devido a uma distância das análises tradicionais, altamente preocupadas com questões de segurança internacional da "high politics", abrindo espaço para que a agenda chamada "soft" tivesse cada vez mais oportunidade no debate nas RI, como com a questão de gênero. Porém, Tickner não concorda com a ideia de que houve um "movimento de inclusão das mulheres em RI" após a Guerra Fria e durante o terceiro debate. Para ela, "as mulheres sempre estiveram inclusas no campo, mas encobertas pelas lentes usadas para estudá-lo" (Izadora Xavier do MONTE, 2013, p. 78). Isso porque

uma abordagem investigativa feminista expõe diversas formas que o poder pode assumir para formar o complexo sistema político internacional do jeito que é. Reconhecidamente, os analistas convencionais de relações interestatais falam muito sobre poder. Na verdade eles colocam poder no centro de seus comentários. Esses comentários então são presumidamente mais naturalmente compreensíveis por homens, as mulheres, especialmente aquelas consideradas naturalmente femininas, alegadamente não possuem um gosto inato por entender ou possuir o poder (Cynthia ENLOE, 1989, p. 352 [tradução livre]).'

No âmbito das RI, há algumas teorias que analisam o sistema internacional através do estudo de gênero como categoria de análise, a fim de explicar disparidades na formulação de identidades de homens e mulheres em instituições e normas. A análise do poder do gênero nas RI é importante não apenas para mulheres individualmente, historicamente marginalizadas em suas diferentes características e particularidades, mas também por influenciar na formação de instituições internacionais e domésticas dos Estados.

Quando compreendemos que a diferenciação entre masculino e feminino não é apenas uma característica individual, mas um conjunto de normas e significados que perpassa os indivíduos, ao mesmo tempo que oferece a esses elementos para a construção de suas identidades, podemos entender o gênero como categoria também presente em discursos e instituições, e em diferentes níveis da vida social - inclusive no nível internacional (MONTE, 2013, p. 69).

O uso de gênero como uma categoria de análise será compatível com teorias das RI que se preocupam, primordialmente, com a justiça, a moralidade e a ética no sistema internacional, com o surgimento histórico do Estado e com as relações entre poder e conhecimento na organização da política estatal. Como afirmam Peterson e Runyan (1999 apud MONTE, 2013), "é comum que mulheres em posições de poder adotem uma atitude masculinizada para se adaptar melhor às demandas" (p. 71), reforçando a ideia de que gênero não é apenas um atributo cultural, mas também algo presente dentro das instituições. É mister, então, que as mudanças ocorram não apenas individualmente, quando mulheres são postas em posições de autoridade, mas no ponto de vista e nas políticas das principais instâncias de poder em nossa sociedade.

' Após o livro pioneiro de Enloe, Robert O. KEOHANE, no mesmo ano de 1989, convidou - em seu conhecido artigo "International relations theory: Contributions of a feminist standpoint" (KEOHANE, 1989) - as feministas a se unirem ao institucionalismo neoliberal, rejeitando outras visões, como a das pós-modernistas, que ele identificou como menos úteis para a teoria feminista. Cynthia WEBER, em 1994, rebate as ideias de Keohane argumentando que ele estava retomando imposições de limites sobre o pensamento feminista. Segundo a autora, ele estaria "sequestrando ideias feministas, removendo partes da literatura que ele não gosta e moldando aquelas que ele concorda com as suas próprias teorias, assim trazendo feministas em linha com as teorias convencionais de Rl" (WEBER, 1994, p. 347). 
Os papéis tradicionalmente designados às mulheres, como de reprodução e cuidados com o lar, são geralmente considerados contribuições irrelevantes para o campo de estudo das RI, resultando numa menor participação das mulheres como tomadoras de decisão quando o assunto são conflitos armados e guerras (TICKNER, 1992). Assim, para a autora, as vozes das mulheres não têm sido legitimadas nas questões de guerra e segurança; elas foram associadas de forma estereotipada, com idealizadoras versões de paz.

Em um contexto de uma sociedade dominada pelos homens, a associação de homens com a guerra e mulheres com a paz também reforça hierarquias de gênero e falsas dicotomias que contribuem para a desvalorização de mulheres e da paz. A associação de mulheres à paz e ao idealismo em RI, como já afirmei, é um conceito profundamente desigual de gênero (TICKNER, 2001, p. 59 [tradução livre]).

Essas características, de modelo ocidental, da masculinidade como agressão, competitividade, poder, afirmação de autonomia, são definições que se alinham com os fundamentos do comportamento estatal designado pelas teorias clássicas positivistas. Dessa forma, essa característica tenta ser desconstruída pelas teorias pós-positivistas que contenham o gênero como categoria de análise e horizonte normativo.

Perspectivas feministas devem introduzir a problemática da violência doméstica e analisar como os limites entre o público e privado, doméstico e internacional, político e econômico, são permeáveis e inter-relacionados (TICKER, 1992, p. 17 [tradução livre]).

Essas caracterizações simplistas da violência como "os homens exploram, as mulheres são exploradas, reforçam estereótipos entre homens e mulheres, são historicamente promotoras de inferioridade e não são efetivas para promover estratégias contra a opressão" (Chandra Talpade MOHANTY, 2008, p. 12). Reparando nos impactos das guerras sobre as mulheres, pode-se observar as relações desiguais de gênero que sustentam as atividades militares. De acordo com Tickner (2001), "a guerra é uma construção cultural baseada em mitos de proteção, e que não é inevitável, como os realistas sugerem" (p. 51).

Na década de 1990, a terceira onda do movimento feminista desencadeou, dentro dos estudos de gênero e da Teoria Feminista das Rl, divergências de pensamento. Na organização de mulheres, principalmente na década de 1990, se vê uma tentativa de homogeneização de suas demandas compatíveis com Direitos Humanos Universais. Apesar de efetiva, essa universalização enfrenta desafios, tanto do estudo de gênero e em sua teorização em Relações Internacionais, com suas diferentes vertentes como, também, na caracterização dessas normas como sendo de Primeiro Mundo, sobretudo pela crítica das feministas pós-coloniais:

Pressupor "mulheres" como um grupo já constituído e coerente, com interesses e desejos idênticos sem importar a classe social, a localização ou as contradições raciais ou étnicas, implica uma noção de diferença sexual ou de gênero, ou uma noção de patriarcado que pode ser aplicada de forma universal e a todas as culturas (MOHANTY, 2008, p. 5 [tradução livre]).

A questão da violência contra a mulher, principalmente em conflitualidades violentas, ocorre predominantemente no Sul global, onde se evidencia uma maior quantidade e/ou ocorrência dos conflitos - internos ou internacionais - tanto histórica quanto atual. Dessa forma, Mohanty (2008) também afirma ser importante "interpretar e teorizar a violência masculina, nas sociedades específicas em que elas ocorrem para assim compreendê-las melhor e ser possível determinar de forma mais eficaz sua transformação" (p. 7). A criação de TANs envolve esses esforços em busca dos direitos das mulheres, que incluam as diferentes demandas regionais e possam impactar na incorporação de suas questões na agenda 
internacional, bem como no desenvolvimento de diretrizes institucionais e políticas, além de mudanças no comportamento dos Estados e de organizações locais e internacionais.

\section{A violência contra a mulher na Agenda Internacional e o desenvolvimento de TANs de mulheres}

Temáticas como o meio ambiente e os direitos das mulheres claramente transbordam fronteiras e, então, têm mais probabilidade de receberem atenção de Organizações Não Governamentais (ONGs) tanto locais, como internacionais. Assim, as TANs geram atenção a questões e auxiliam a determinar agendas quando, segundo Keck e Sikkink (1999), "provocam atenção da mídia, debates e reuniões [em relação a] problemáticas anteriormente não vistas de forma relevante na discussão pública" (p. 98).

Os esforços de ativistas dos direitos das mulheres se diferenciam de outros defensores de ONGs por constituírem um dos setores mais organizados das últimas décadas, onde, além de clamar atenção para seus problemas específicos, conseguiram integrar suas demandas em outras lutas, ocasionando o que Friedman (2003) chamou de "gendering the agenda" (p. 313), ou seja, colocando a questão de gênero de forma multidisciplinar na agenda internacional.

As bases para a luta pela diminuição da violência contra a mulher emergiram de movimentos locais de mulheres em suas comunidades, particularmente na América Latina e na Ásia, principalmente pelo caso das "mulheres de conforto". ${ }^{2}$ Essas mulheres eram forçadas à prostituição em bordéis "oficiais" do exército imperial japonês, ao longo dos anos 1930 até o final da Segunda Guerra Mundial. Autorizada pelo Governo Imperial do Japão, a escravidão sexual ocorreu de forma sistemática durante a Guerra do Pacífico (1937 a 1945), com as vítimas sendo mulheres jovens, pobres e também de países na época colônias japonesas, como a Coréia. Estimativas da Anistia Internacional conferem que mais de 200.000 mulheres foram tidas como escravas sexuais por esse exército durante o conflito (AMNESTY INTERNATIONAL, 2015).

O primeiro conceito oficial desenvolvido para "violência contra a mulher" não foi feito pelas Nações Unidas, mas sim pela Organização dos Estados Americanos (OEA) apenas em 1994, no âmbito da Convenção Interamericana para Prevenir, Punir e Erradicar a Violência Contra a Mulher que era conceituada como "qualquer ato ou conduta baseado em gênero, que cause morte ou danos físicos, sexuais ou psicológicos, ou sofrimento à mulher, seja na esfera pública ou privada" (KECK; SIKKINK, 1998, p. 172 [tradução livre]).

Durante o período da primeira onda até os anos 1960, as únicas diretrizes internacionais relacionadas à questão das mulheres e da violência eram: a Quarta Convenção de Genebra de 1949, que é um dos principais instrumentos de proteção às vítimas de conflitos armados, que contém provisões relevantes para as mulheres, mas de uma forma limitada e com uma maior atenção para crianças e mães em geral, e uma subcomissão para tratar sobre a "Condição da Mulher", estabelecida na la Assembleia

\footnotetext{
2 Uma das situações mais marcantes desse período foi o Massacre ou Estupro de Nanquim, cenário de diversas atrocidades como o estupro e assassinato de um número estimado entre 20 mil a 80 mil mulheres chinesas pelas tropas japonesas, incluindo grávidas, jovens e idosas. Hoje, 70 anos após as violências cometidas durante um curto período de seis semanas, o governo japonês continua livre de responsabilidades legais e morais referentes a esses crimes de guerra. As mulheres que sobreviveram e suas famílias ainda aguardam por justiça, memória e verdade por parte do estado japonês. Para que essas ações desumanas e cruéis não caiam no esquecimento, é importante ressaltar também "a falta de uma posição mais enfática da comunidade internacional quanto ao caso, transparecido pela falta de execução de sanções relativas à condenação do Japão por seus crimes de guerra pela ONU" (Julia Yuri OKAMOTO, 2013, p. 107).
} 
Geral da ONU, em 1945, pelo Conselho Econômico e Social. Além disso, no início do século XX, o foco foi a problemática do Tráfico de Pessoas e exploração sexual, tendo sido incorporada em convenções internacionais, como a "Convenção para a Supressão do Tráfico de Pessoas e da Exploração da Prostituição de Outrém”, de 1949.

Três Conferências foram primordiais para os avanços que os direitos das mulheres teriam na agenda internacional: Cidade do México (1975), Copenhague (1980) e Nairóbi (1985). Considerada a Década da Mulher, o "advocacy" nesse período aumentou a atenção para a problemática na agenda internacional. O ponto crucial defendido pelos movimentos de mulheres, assim como pela teoria feminista, era "o pessoal é político", rompendo com o que até então era caracterizado como exclusivamente público ou privado. Pode-se fazer uma grande analogia com a violência doméstica que, em consequência, foi o eixo de preocupação inicial do decênio. Posteriormente, expandiu-se para as diversas outras formas de violência, como, por exemplo, mulheres em detenção e durante conflitos armados.

A primeira Conferência do Decênio foi na Cidade do México, em 1975, realizada para celebrar o então declarado pela ONU Ano Internacional da Mulher, e foi hospedeira de um grande debate entre as diferentes demandas dos grupos feministas do Norte e do Sul global. Divergências nas reivindicações dentro do movimento feminista ocorreram concomitantemente com a sua internacionalização, produzindo desafios na criação de uma "irmandade internacional" (Luciana BALLESTRIN, 2015, p. 8).

As oportunidades de acesso das ONGs às agendas governamentais durante as Conferências da Década da Mulher se expandiram lentamente. A participação civil foi inicialmente restrita, no México, em 1975, com apenas dois representantes por ONG credenciados e autorizados a participar. Segundo Fraser (1987 apud FRIEDMAN, 2003), "havia, no início dos anos 1980, uma complexa rede de mulheres ativistas se comunicando através de diversas mídias informais, despercebidas pela mídia tradicional" (p. 318). Na conferência de Copenhague, em 1980, foi formulada uma resolução sobre a violência na família, fazendo um apelo contra a violência familiar e para acabar com o abuso físico e mental de mulheres e crianças. Houve também uma maior adesão no número de mulheres participantes, bem como representações de todos os continentes, aumentando o intercâmbio entre diferentes grupos organizados de mulheres.

Em Copenhague, o retorno dessas novas estratégias, bem como o início de demandas compartilhadas entre ativistas, pode ser visto na crescente sofisticação das análises das situações das mulheres ao redor do mundo, e o reconhecimento da necessidade de uma organização unida de mulheres (FRIEDMAN, 2003, p. 318 [tradução livre]).

Os atritos causados pelas diferenças ao elencar as demandas primordiais para cada região foram moderadamente aliviados na Conferência de Nairóbi, em 1985, onde, pela primeira vez, se fez recomendações diretas e claras à questão da violência contra a mulher, e pôde ser identificada uma convergência entre todos os grupos de mulheres ao redor do mundo para essa problemática. Nairóbi foi o primeiro passo para a fixação do tema da violência contra a mulher na agenda internacional, por desencadear uma mudança na posição discursiva dos governos e por aproximar os grupos de mulheres que trabalhavam com a temática. Assim, a chamada Década da Mulher, que contempla as três conferências anteriormente citadas, foi extremamente relevante para consolidar as TANs entre grupos de mulheres. É importante citar que "Conferências Internacionais não criaram o network das mulheres internacionalmente, mas elas legitimaram os problemas e trouxeram um número vasto de mulheres ao redor do mundo" (KECK; SIKKINK, 1998, p. 169).

Em 1979, foi adotada a Convenção para a eliminação de todas as formas de discriminação contra a mulher (CEDAW), que entrou em vigor em 1981. Segundo o site da 
UN Women, essa Convenção resultou num instrumento jurídico internacional vinculativo para todos os Estados-parte das Nações Unidas. A convenção "define a discriminação contra as mulheres, identifica as variadas formas de discriminação e estabelece uma agenda de ação nacional para acabar com todas as formas de discriminação contra as mulheres". Da mesma forma, os Estados são responsáveis por tomar as medidas cabíveis para promover os direitos das mulheres, bem como apresentar relatórios, periodicamente, sobre as medidas tomadas. Apesar de a Convenção original não ter mencionado de forma explícita a violência contra as mulheres e meninas, foram feitas recomendações gerais que incluíam a temática, mas visivelmente ainda não era um assunto de extrema relevância na agenda internacional.

Essa falta de estímulo para inserir a violência contra a mulher de forma efetiva e definitiva na agenda internacional pode ser entendida devido ao fato de que a discriminação e desigualdade eram as principais lutas dos movimentos na Europa, nos EUA e no sistema da ONU, o que muitas vezes não representava as demandas dos grupos do Terceiro Mundo, focados principalmente para a questão da violência. Após a Conferência de Nairóbi, em 1985, percebeu-se grande pressão em relação à incorporação da temática da violência contra a mulher como problemática institucionalizada. Tanto que, em 1987, a ONU organizou uma reunião e autorizou um estudo sobre "Violência contra a mulher na Família". Essa foi a primeira ação concreta da ONU, específica sobre a questão da violência.

Os preparativos para a Conferência de Viena de 1993 evidenciaram a aproximação dos grupos de mulheres e fortalecimento de TANs, clamando atenção para suas demandas e delimitando agendas para Estados e organizações internacionais, na mesma medida em que incitaram uma associação entre os grupos de mulheres com os grupos de Direitos Humanos. Nesse momento, mulheres representantes do Norte e Sul global foram capazes de incluir os abusos contra as mulheres como um direito humano fundamental, através de ações regionais e globais, lobbying em encontros preparatórios regionais e na escuta de depoimentos de diversas mulheres.

É importante citar que a participação em Conferências e a comunicação de grupos de mulheres foi altamente facilitada a partir da década de 1990, devido à difusão de novas tecnologias, como o fax e a internet. Assim, "mais de 3.000 participantes representando 1.500 ONGs de todas as regiões do mundo participaram na conferência de Viena, sendo $49 \%$ mulheres" (KECK; SIKKING, 1998, p. 187). Dessa forma, o principal resultado desse trabalho de networks foi a inserção dos direitos das mulheres na agenda dos direitos humanos, em que o documento final da conferência reconhece a violência de gênero, incluindo estupro e escravidão sexual, e todas as formas de assédio e exploração sexual como uma questão de direito humano fundamental.

Os Direitos Humanos das mulheres e das crianças do sexo feminino constituem uma parte inalienável, integral e indivisível dos Direitos Humanos universais. A participação plena das mulheres, em condições de igualdade, na vida políica, civil, econômica, social e cultural, aos níveis nacional, regional e internacional, bem como a erradicação de todas as formas de discriminação com base no sexo, constituem objetivos prioritários da comunidade internacional (DECLARAÇÃO E PROGRAMA DE AÇÃO DE VIENA, 1993).

Segundo Keck e Sikkink (1998), as TANs alcançam seus objetivos quando progridem através de cinco etapas: criação da problemática e definição de agenda; influência sobre a posição discursiva de Estados, Organizações Regionais e Internacionais; influência em procedimentos institucionais; influência na mudança de política de determinados atores (estatais, intergovernamentais ou privados); influência no comportamento dos Estados. No caso das TANs de mulheres após a Conferência de Viena, já teriam sido alcançados os dois 
primeiros estágios, colocando a questão de enfoque, a violência contra a mulher, na agenda internacional e alterando os discursos de Estados e Organizações, mesmo que ambos de forma limitada.

A inserção dos direitos das mulheres como um Direito Humano foi a abertura de uma porta sem precedentes para futuras realizações em prol da defesa dos direitos das mulheres no meio internacional. Entretanto, gerou diversos debates que acaloraram as especificidades existentes dentro da própria análise de Direitos Humanos e entre o ativismo local de mulheres ao redor do mundo. Sobre isso, Charlotte BUNCH (2001) afirma que "o desafio é reconciliar o reconhecimento e a força da multiplicidade de experiências de mulheres, com a necessidade de encontrar uma base comum para a colaboração das mulheres numa rede internacional" (p. 377).

Também é importante salientar que, com essa inclusão, os termos feministas anteriormente usados de forma intensa pelo movimento de mulheres sofreram um desaparecimento perceptível, não apenas nos documentos oficiais, mas também nos confeccionados por indivíduos e grupos, sendo mais aceitável discursar sobre os Direitos Humanos das Mulheres (Joan McFARLAND, 1998).

Viena trouxe uma tentativa de conciliar a diversidade dentro do próprio movimento e estimular alianças globais, baseadas em agendas e objetivos comuns, principalmente fazendo com que a voz do movimento seja ouvida e abra precedentes maiores para prestação de contas, por parte dos Estados, baseada em uma abordagem integrativa. Porém, muitas ativistas de países semiperiféricos não concordam com essa ideia, o que será mais explorado na próxima seção deste artigo.

Especificamente sobre a questão das mulheres em conflitos armados, a Declaração e Programa de Ação de Viena evidencia que:

A Conferência Mundial sobre Direitos Humanos apela à Assembleia Geral para que adote o projeto de declaração sobre a violência contra as mulheres, e instigue os Estados a combaterem a violência contra as mulheres em conformidade com as disposições contidas na declaração. As violações dos direitos das mulheres em situações de conflito armado constituem violações dos princípios internacionais fundamentais de Direitos Humanos e de Direito Humanitário. Todas as violações deste tipo, incluindo especialmente, o homicídio, as violações sistemáticas, a escravatura sexual e a gravidez forçada exigem uma resposta particularmente eficaz (DECLARAÇÃO E PROGRAMA DE AÇÃO DE VIENA, 1993, III, 3, 38).

Dessa forma, em 1993, foi adotada pela Assembleia Geral a Declaração sobre a Eliminação da Violência contra as Mulheres, ${ }^{3}$ que traz constatações importantes para a comunidade internacional, como as encontradas no seu preâmbulo:

Reconhecendo que a violência contra as mulheres constitui uma manifestação de relações de poder historicamente desiguais entre homens e mulheres, que conduziram ao domínio e à discriminação das mulheres por parte dos homens e impediram o progresso pleno das mulheres, e que a violência contra as mulheres constitui um dos mecanismos sociais fundamentais através dos quais as mulheres são forçadas a assumir uma posição de subordinação em relação aos homens (DECLARAÇÃO SOBRE A ELIMINAÇÃO DA VIOLÊNCIA CONTRA AS MULHERES, A/RES/48/104, Preâmbulo, 1993).

\footnotetext{
${ }^{3}$ Deve-se notar que a Declaração sobre a Eliminação da Violência contra a Mulher não é uma convenção ou tratado, tampouco uma fonte primária de direito internacional. No entanto, as resoluções da Assembleia Geral da ONU são declarações de autoridade na comunidade internacional.
} 
Também em 1993, importante ano para as mulheres, foi criado o Tribunal Penal Internacional para a Antiga lugoslávia, ${ }^{4}$ que incluía acusação de violência sexual e respostas internacionais ativas no que concerne à violência sexual em conflitos, como apresentação de provas. No ano seguinte, seguindo o modelo do Tribunal Internacional para a ex-lugoslávia, o Tribunal Penal Internacional para Ruanda (ICTR, em inglês) foi criado pelo Conselho de Segurança da ONU através da resolução 955/1994. O ICTR foi o primeiro tribunal a reconhecer estupro como uma forma de genocídio e também o primeiro a condenar uma pessoa pelo crime de genocídio 5 (UN WOMEN, 2015).

Tal qual a Declaração para a Eliminação da Violência contra a Mulher, a Plataforma de Ação de Pequim em $1995^{\circ}$ reconhece a violência sexual como "um obstáculo para a igualdade, o desenvolvimento e a paz" e faz referência para a "violação dos direitos humanos das mulheres em situação de conflitos armados, em particular, assassinato, estupro sistemático, escravidão sexual e gravidez forçada". Assim, faz recomendações para que todos os oficiais, atuantes em conflitos, sejam treinados em direito humanitário e direitos humanos, e que a punição para agressores seja efetiva.

De forma relevante, a Plataforma de Ação de Pequim de 1995 proclamou que "Paz é intrinsecamente ligada com a igualdade de desenvolvimento entre mulheres e homens". Especialistas apontam que a principal contribuição de Pequim 1995 é a articulação de uma visão ampla das mulheres nos conflitos armados, incluindo-as como vítimas de violência sexual. Apesar de em Pequim ser reconhecida a seriedade do impacto dos conflitos armados nas mulheres e sua Declaração ter determinado a participação dos Estados para assegurar respeito ao Direito Internacional Humanitário, especialmente às normas que dizem respeito às mulheres e meninas, ficou claro que essas declarações, como as de outras conferências, são apenas discursos políticos e simbólicos que não vinculam responsabilidades para os Estados. Porém, elas criam precedentes para que haja uma maior pressão de movimentos organizados de mulheres da sociedade civil que possam demandar atenção para a problemática e, principalmente, requerer ações de maneira legitimada.

Outras importantes diretrizes no âmbito da violência contra a mulher foram realizadas na década de noventa e impactaram a observância de procedimentos durante conflitos armados. A criação do Fundo de Desenvolvimento das Nações Unidas para a Mulher (UNIFEM) em 1996 e o estabelecimento do Tribunal Penal Internacional, em 1998 - tribunal que julga e condena crimes de gênero e violência sexual no contexto de crimes de guerra, crimes contra a humanidade e genocídio -, são dois exemplos. Foi também designada uma unidade específica para gênero e crianças a fim de melhorar a investigação e o processo de crimes relacionados com a desigualdade de gênero, incluindo estupro e outras formas de violência sexual contra mulheres e crianças. Já no âmbito da sociedade

\footnotetext{
${ }^{4} \mathrm{Em} 25$ de maio de 1993, o Conselho de Segurança da ONU aprovou a Resolução 827, que estabeleceu formalmente o Tribunal Penal Internacional para a ex-lugoslávia, conhecido como o ICTY (em inglês) (ICTY, 2015).

${ }^{5}$ No dia 2 de setembro de 1998, o ICRT proferiu uma sentença de condenação por crime de genocídio, a primeira em toda a história humana, para o caso de Akayesu. Deve-se notar que o réu Akayesu não foi condenado por estuprar mulheres nem por ordenar a violência contra mulheres (embora ele tenha ordenado um ato de violência sexual). Ele, no entanto, foi condenado por estupro, porque ele era um oficial em uma posição de responsabilidade quando os atos de estupro foram realizados por seus subordinados e, apesar de ciente deles, ele não tomou medidas para prevenir estes atos ou punir os autores deles (INTERNATIONAL AMNESTY, 2005).

${ }^{6}$ Em 1995, aconteceu em Pequim a Quarta Conferência Mundial sobre as Mulheres. A Comissão sobre o Status da Mulher tem sido responsável pela organização e acompanhamento das conferências mundiais sobre as mulheres no México (1975), Copenhague (1980), Nairóbi (1985) e Beijing (1995) (UN, 2015).
} 
civil global houve a Conferência da Cruz Vermelha e do Crescente Vermelho, em 1996, que adotou por consenso uma resolução a fim de lidar separadamente com a questão da violência sexual contra mulheres em conflitos.

No século XXI, a primeira ação relacionada aos direitos das mulheres foi a Resolução 1325/2000 do Conselho de Segurança da ONU, chamada "Mulher, Paz e Segurança", que reconheceu como os impactos da guerra atingem as mulheres de forma diferente, e reafirmou a necessidade de uma maior participação das mulheres nos processos de decisões (decision-making) em relação à prevenção e resolução de conflitos (UNSC, Resolução $1325 / 2000)$.

Realça a responsabilidade que todos os Estados têm de pôr fim à impunidade e processar os responsáveis por genocídio, crimes contra a humanidade, e crimes de guerra, incluindo os que se relacionam com o sexo e qualquer outro tipo de violência contra as mulheres e as meninas, e, a este propósito, sublinha a necessidade de, sempre que possível, excluir tais crimes das provisões de anistia (RES 1325/2000, Parágrafo 11).

A Resolução foi adotada por unanimidade de votos pelos membros do Conselho de Segurança, à época composto por: Argentina, Bangladesh, Canadá, Jamaica, Malásia, Mali, Namíbia, Holanda, Tunísia e Ucrânia, como também os membros permanentes, China, França, Rússia, Reino Unido e Estados Unidos. Seguindo a Resolução 1325, o Conselho de Segurança nos anos posteriores emitiu outras resoluções tratando especificamente sobre a observância dos direitos das mulheres em conflitos armados. Essas diretrizes têm o objetivo de definir obrigações aos Estados-membros das Nações Unidas, e, assim, forçar que os Estados desenvolvam planos de ações nacionais para alcançar essas metas. Porém, elas barraram em grandes desafios, como vontade política e falta de recursos adequados.

A ação mais recente encontrada das Nações Unidas para a violência contra a mulher, além das Resoluções renovadas no Conselho de Segurança, foi a Campanha global UNITE to End Violence against Women, em 2008, que invoca a atenção de governos, sociedade civil, organizações de mulheres, jovens, setor privado, mídia e todo o sistema das Nações Unidas sobre a temática. O principal objetivo é pressionar pela adoção e cumprimento de leis nacionais para combater e punir todas as formas de violência contra mulheres e meninas; adoção e implementação de planos de ação nacionais multissetoriais; reforçar a coleta de dados sobre a violência contra mulheres e meninas; aumentar a consciência pública e mobilização social; e abordar a temática da violência sexual em conflitos até 2015 (UNITE CAMPAIGN, 2009).

Em síntese, os avanços gerados desde a década de 1970 até hoje foram grandiosos para a luta em defesa dos direitos das mulheres, principalmente no combate à violência contra a mulher. Percebe-se que a influência de TANs voltadas para as mulheres, em desenvolvimento durante a década da mulher e efetivamente fortalecida durante os anos 1990, trouxe impactos como a colocação da temática na agenda internacional, a mudança discursiva de atores do sistema internacional, bem como a criação de procedimentos institucionais, tanto domésticos quanto internacionais. Identifica-se, também, que após a consideração dos direitos das mulheres como um direito humano fundamental, em Viena, em 1993, houve a incorporação, de fato, da temática da violência contra a mulher na agenda internacional, sendo que seu escopo se expandiu, criando uma maior preocupação e atenção também no âmbito de conflitos armados, reconhecidas pelas diretrizes durante a Conferência de Pequim em 1995 


\section{Violência contra a mulher durante conflitos armados}

A violência contra a mulher pode assumir diversas formas inter-relacionadas - físicas, sexuais, psicológicas e econômicas. Os tipos mais conhecidos são: violência cometida por um parceiro íntimo, violência sexual, violência sexual em conflitos, mutilação genital, tráfico. Dentre elas, algumas, como o tráfico de mulheres e a violência durante conflitos, podem transbordar as fronteiras nacionais de Estados.

A violência sexual ainda é a mais citada durante os conflitos armados, principalmente pelo esforço em colocar essa temática na agenda nos anos 1990, após centenas de milhares de mulheres terem sido vítimas nos conflitos da ex-lugoslávia e Ruanda. Porém, muitas outras formas atingem as mulheres em proporções diferentes aos homens, a exemplo do fato de que as mulheres e crianças são a maioria dos refugiados e deslocados devido a situações de conflito.

Autoras como Keck e Sikkink também defendem que, além das atrocidades cometidas nos períodos beligerantes da década de 1990 que alavancaram atenção para o tema, visões de crueldade física tendem a ser mais aceitáveis através de diferentes culturas do que os impactos causados de forma psicológica ou emocional. Assim, o foco na problemática da violência sexual agregaria as necessidades das mulheres amplamente ao redor do mundo.

Apesar do tema da discriminação também ser extremamente relevante, a violência contra a mulher, especificamente, ganhou mais notoriedade e influenciou mais rapidamente mudanças institucionais. A questão da violência, por agregar mais as demandas do Sul e Norte global, conseguiu conciliar mais e criar um movimento mais global (KECK; SIKKINK, 1998, p. 197).

Segundo Jeanne WARD and Mendy MARSH, em seu relatório de 2006, "Sexual Violence Against Women and Girls in War and lts Aftermath: realities, responses, and required resources", as estatísticas desde 1996 são perturbadoras, mostrando o quão frequente a violência sexual em conflitos se tornou.

Pode ser argumentado que as estatísticas atuais apenas reflitam a maior atenção internacional para o assunto - provocado em parte pela cobertura da mídia das atrocidades sexuais cometidas durante os conflitos da Ex-lugoslávia e Ruanda, e de forma mais importante, pelas décadas de esforço intensivo de conscientização feito por mulheres ativistas ao redor do mundo - do que um aumento absoluto significante do número de vítimas. A explicação mais provável, porém, é que a natureza da guerra está mudando, se tornando cada vez mais perigosa para mulheres e meninas (WARD; MARSH; 2006, p. 3).

Com base no mesmo relatório, se estima que, entre 1989 e 1997, 103 conflitos armados iniciaram em 69 países. As fatalidades de civis são contabilizadas em $75 \%$, um contraste impressionante com os $5 \%$ desde o início do século passado. Apesar de a maioria das fatalidades ainda ser relacionada aos homens, as mulheres sofreram um aumento significativo das consequências impactantes trazidas pelas guerras.

Como já argumentado pela Teoria Feminista das RI, existe uma conceitualização da guerra e da paz de forma estereotipada. Frequentemente, as vozes das mulheres são relacionadas a versões idealizadas de paz e raramente ganham legitimidade em matéria de guerra e segurança (TICKNER, 2001). Dessa forma, durante conflitos armados se identifica uma persistente "feminilização" do oponente, com o uso de violência psicológica e muitas vezes física, como o estupro ou até a castração de homens, para se utilizar do poder de gênero e simbolizar a dominação do inimigo. Assim, na codificação da guerra é "normal" 
se utilizar de uma posição dominante e supostamente tida como masculina, em relação ao seu subordinado, que é sempre tido como feminino e inferior (Joshua S. GOLDSTEIN, 2001).

Nota-se que a influência em diretrizes institucionais alcançadas pelas TANs pode ser compreendida no reconhecimento, a partir da metade dos anos 1990, do estupro e outras formas de violência sexual como crimes dentro do direito humanitário, e também na pressão para punição de agressores, que culminou na criação de Tribunais Internacionais. A adoção do Estatuto de Roma no Tribunal Penal Internacional, em 1998, frisou a gravidade dessa forma de violência, destacando, em seu Artigo $8^{\circ}, \mathrm{XXII}$, que

cometer atos de violação, escravidão sexual, prostituição forçada, gravidez à força, tal como definida na alínea f) do parágrafo 20 do artigo 70 , esterilização à força e qualquer outra forma de violência sexual que constitua também um desrespeito grave às Convenções de Genebra.

As diversas motivações para se cometer o crime de violência durante conflitos armados variam. Podem ser de forma aleatória, como um subproduto do colapso na ordem social e moral que acompanha a guerra; podem ser sistemáticas, realizadas por forças que lutam para o propósito explícito de desestabilizar as populações, destruindo laços de comunidades e famílias; podem servir para sufocar a resistência, inserindo o medo em comunidades ou na oposição a grupos armados (Megan BASTICK; Karin GRIMM; Rahel KUNZ, 2007).

Também, particularmente em conflitos definidos por questões raciais, tribais, religiosas e outras, a violência pode ser usada para promover a limpeza étnica como, por exemplo, os estupros públicos na Bósnia, que foram utilizados como uma forma de causar a fuga ou expulsão de comunidades muçulmanas. Casos de mulheres e meninas que foram raptadas para fornecer serviços sexuais para combatentes também podem ser um meio de manifestação da violência sexual em conflitos armados.

Nadine Puechguirbal, coordenadora da United Nations Action against sexual violence in conflict (2014), lamenta que membros de diferentes organizações humanitárias convençam seus interlocutores a defender o argumento de que não é o momento certo para lutar contra as questões de gênero, afirmando que o problema assume cada vez mais relevância dentro das atividades das organizações. Porém, argumenta que ainda há muito o que se fazer antes de focar na violência contra a mulher em conflitos:

Essas afirmações se tornaram parte de um cenário político de organizações internacionais, e homens e mulheres repetem sem medirem o impacto da perpetuação de estereótipos e preconceitos que retardam o processo em direção à igualdade de gênero. Não podemos permitir que o patriarcado conduza a agenda política e estabeleça normas de gênero que apenas perpetuam a violência, em linguagem e ação (UNITED NATIONS, 2014, p. 33 [tradução livre]).

No relatório Women \& Armed Conflicts and the issue of Sexual Violence (COLLOQUIUM ICRC - EUISS, 2014) defende-se que "o problema não reside tanto na falta de regras mas sim na falta de um compliance adequado dessas regras" (p. 22). De acordo com a mesma autora, no que diz respeito à falta de observância das normas, dois elementos podem ser identificados: o frequente senso de impunidade e o fato de que essas violações dos direitos fundamentais das mulheres, no âmbito de conflitos armados, não são tão importantes; são aceitáveis devido ao seu contexto.

Referente à impunidade, muito se avançou desde os anos 1990, principalmente pelos Tribunais Internacionais ad hoc e o Permanente. Entretanto, muitos casos de violência ainda não são reportados, por medo ou falta de apoio estrutural para tal, bem como a 
maioria dos que são denunciados não consegue um julgamento efetivo. Os fatos históricos nos mostram que a atenção para essa temática só é grande quando as tragédias são devastadoras e atingem milhares de mulheres. Essa preocupação deve ser expandida para casos isolados da mesma forma e na mesma intensidade.

O segundo elemento que nos diz respeito em relação à falta de importância da violência contra as mulheres em conflito, considerando-a "efeito colateral" do que se está vivenciando, é muito próximo das percepções teóricas realistas, ainda altamente presentes no desenvolvimento das diretrizes políticas no sistema internacional. Da mesma forma, o Comitê Internacional da Cruz Vermelha ( $\mathrm{ClCV}$ ) também defende que "há regras suficientes no direito humanitário internacional para prevenir a violência contra a mulher em conflitos armados. Porém, o problema real é a falha na implementação dessas regras". Segundo o $\mathrm{CICV}$, as mulheres ainda enfrentam dificuldades massivas e desproporcionais durante períodos de guerra, porque as regras existentes não são observadas adequadamente (AMNESTY INTERNATIONAL, 2005, p. 68).

Por outro lado, muitas críticas feministas acreditam que a principal falha é a linguagem das regras do direito humanitário internacional, bem como de outras normas que dizem respeito às mulheres, por refletirem estereótipos de gênero que perpetuam a discriminação e a violência em si. É importante a percepção dos impactos divergentes entre homens e mulheres nos conflitos armados, mas o persistente uso de termos que transmitam a ideia de que mulheres são sempre as "vulneráveis", as que têm uma "honra" para assegurar, reforça a dicotomia já defendida por Tickner da relação da mulher com a Paz e do homem com a Guerra, mantendo esse assunto masculinizado também na esfera política e na institucionalização de regras.

É necessário reforçar a ideia de que a guerra não é algo inevitável, mas sim uma construção social baseada principalmente nos "mitos de proteção" (TICKNER, 2001). Os efeitos irreparáveis de violência, tanto física como psicológica, e o impacto degradante da guerra em civis mostram como é equivocada essa ideia de legitimar os conflitos baseados num princípio de proteção.

\section{Obstáculos para a afirmação dos direltos das mulheres a nível internacional}

A efetividade de TANs voltadas para as mulheres pode ser compreendida pelo fato de que antes das suas campanhas de maior esforço, nos anos 1990, o tema da violência contra as mulheres não estava na agenda política. Não havia sido incluído na Conferência do Ano Internacional da Mulher no México, em 1975, tampouco na Convenção sobre a Eliminação de todas as formas de Discriminação contra as Mulheres, de 1979. Já na Conferência de Pequim, em 1995, foi um dos tópicos mais discutidos e o de principal atenção em seu documento final. Isso demonstra a evolução importante que o assunto teve em 20 anos, saindo de uma questão sem atenção internacional para um nível elevado de conscientização e importância.

Uma importante conquista, já citada nesse artigo, foi a inclusão dos Direitos das Mulheres no escopo dos Direitos Humanos, criando uma oportunidade para que as demandas dos grupos de mulheres alcançassem mais facilmente os Estados. Esses grupos já haviam acordado por diversos tratados internacionais em observar os Direitos Humanos em seus territórios. Assim, com a incorporação das demandas das mulheres nesse quadro, seria mais fácil argumentar a obrigação dos Estados em seguir essas diretrizes.

O termo violência auxiliou mulheres a superarem esse improdutivo debate norte-sul criando uma nova categoria: quando esposa agredida ou estupro nos EUA, mutilação 
genital na África e as mortes de mulheres causadas pela disputa de seu dote na Índia, foram todas classificadas como formas de violência contra a mulher, assim as mulheres puderam interpretar essas situações como comuns e buscar causas similares (KECK; SIKKINK, 1998, p. 197).

Porém, a inserção no contexto dos Direitos Humanos, que inegavelmente trouxe avanços preciosos para a consolidação dos direitos das mulheres, tanto no âmbito doméstico como internacional e também em conflitos armados, reacendeu os debates importantes presentes na dicotomia dos movimentos do centro e da periferia. De acordo com Joan McFarland, a experiência, particularmente de mulheres do Sul global, é que a abordagem de Direitos Humanos não é muito "eficaz". Segundo ela, existe uma discrepância entre o proclamado pelo discurso dos Direitos Humanos e a experiência real vivida. ${ }^{7}$

As TANs ainda estão absorvendo a inclusão de suas demandas na abordagem dos Direitos Humanos ${ }^{8}$ e algumas ativistas já estão tentando reformular os direitos das mulheres como uma questão de saúde. Isso porque o escopo dos direitos humanos foi importante para aumentar a conscientização, mas a maioria das ativistas teme que não seja efetivo para prevenção e tratamento. Assim, incluí-lo como uma questão de saúde traria maior conscientização e um melhor desenvolvimento de estratégias para o tratamento de vítimas, o que seria extremamente importante para o âmbito da violência durante conflitos armados.

Claramente assimetrias ainda existem dentro das TANs de mulheres com estratégias dominantes dos Estados Unidos e da Europa pelas suas organizações e indivíduos. Mas a emergência de um advocacy comum através da questão da violência contra a mulher é o resultado de uma interação muito mais complexa do que apenas o modelo de "direitos humanos é um imperialismo cultural" (KECK; SIKKINK, 1998, p. 198).

Especialmente no âmbito de conflitos armados, além da superação das diferenças existentes a fim de unificar as demandas das mulheres internacionalmente, é necessário que os Estados em seu nível doméstico demonstrem o reconhecimento da persistente violência contra as mulheres e a importância das mesmas no desenvolvimento das nossas sociedades. Também é importante que desenvolvam vontade política para internalizar e cumprir as diversas normas e resoluções já existentes para impulsionar os direitos das mulheres.

É conhecido que os desafios para as mulheres não encerram com o término do conflito; muitas delas continuam a sofrer com a violência. A falta de dinheiro ou outros recursos, aliada à perda de seus companheiros, que, em muitas sociedades, representam o provedor da casa, faz com que mulheres precisem recorrer à prostituição para obter comida, locomoção, casa e outras necessidades básicas. Assim, enfrentam discriminação devido à violência enfrentada durante o conflito e são expulsas de suas comunidades (WARD; MARSH, 2006).

Como já citado neste artigo, a violência contra a mulher em conflitos armados representa a desigualdade de gênero durante os tempos de paz. É possível analisar que os

\footnotetext{
7 "Celina Romany descreveu os sentimentos das ativistas do Sul na Conferência de Viena: muitas mulheres se sentiram objetificadas pelas mulheres do Norte, que transmitiram a solidariedade romantizada que lembra as construções similares das lutas de classe e raciais. Imprensa e relações públicas, a face dos esforços, nessa conferência, foram controladas por uma minoria. A maioria das mulheres se sentiu como clientes reapresentadas ao mundo pelas defensoras esclarecidas do Norte" (McFARLAND, 1998, p. 58).

8 "Enquanto uma estratégia de direitos humanos das mulheres pode ter o potencial de colocar mulheres da mesa global de policy making, entre as suas principais limitações está o perigo de estar deixando para trás muitas mulheres que se tenta representar. A abordagem dos direitos humanos pode dar ao movimento global de mulheres uma "voz" na mesa do policy making, mas dada a hipocrisia da mesma mesa, é essa voz que fará realmente alguma diferença?" (MCFARLAND, 1998, p. 59).
} 
principais crimes de guerra relacionados com a violência contra a mulher que alcançaram notoriedade foram os que atingiram centenas de milhares de mulheres. As percepções de cumprimento da lei e punições devem ser compreendidas para a valorização de cada mulher, individualmente. Porém, a segurança das mulheres em tempos beligerantes enfrenta um desafio maior, pois como Ward e Marsh (2006) afirmam, "as regras da guerra nunca podem realmente mudar enquanto a agressão violenta contra as mulheres for tolerada na vida cotidiana" (p. 29).

\section{Considerações finais}

Durante o período da Guerra Fria, o embasamento teórico do realismo e liberalismo prevaleceu. Mas, a partir da década de 1980, essa vertente passou a enfrentar dificuldades em analisar os acontecimentos e, assim, criou espaço para que outras concepções teóricas ganhassem força com suas diferentes formas de análise do sistema internacional. Então, as feministas foram as que mais reivindicaram espaço a partir dos anos 1990, tanto na esfera teórica das RI, como também no ativismo, pressionando para que suas demandas fossem incorporadas nos discursos políticos de Estados e Organizações Internacionais.

Dentre as contribuições da Teoria Feminista, uma das mais valiosas foi incitar atenção para as diferenças entre o que era tido como público e privado. Esse raciocínio traz para a análise da violência contra a mulher uma responsabilidade compartilhada por todos, não importando se ocorreu na esfera doméstica ou pública, dentro de um Estado ou internacionalmente. Isso se percebe principalmente na Década da Mulher, iniciada em 1975, onde a violência doméstica foi o ponto inicial de concentração dos debates de grupos de mulheres internacionalmente.

A Década da Mulher foi o primeiro passo para a colocação do tema da violência contra a mulher na agenda internacional. Os grupos de mulheres estavam cada vez mais se fortificando de forma organizada em TANs e houve uma unidade para a luta ao redor da questão da violência. O esforço para inserção de forma relevante desse tópico se deu, primordialmente, por mulheres do Sul global, principalmente da América Latina e da Ásia. A discriminação e a desigualdade foram os temas principais de luta dos países centrais, como Estados Unidos e Europa, o que acarretou demora para inserir efetivamente a violência contra a mulher na agenda internacional. Isso só ocorreu em 1993, com a Conferência de Viena, sobretudo, pela efetiva organização das mulheres em TANs e devido à união dos grupos de mulheres com ativistas de Direitos Humanos.

A comprovação de que a partir de Viena houve a real colocação da violência contra a mulher na agenda internacional foram os eventos que a sucederam, tais como: a adoção pela Assembleia Geral da ONU da Declaração sobre a Eliminação da Violência contra as Mulheres, em 1993, a conceitualização de "violência contra a mulher" pela Organização dos Estados Americanos (OEA), em 1994, na Convenção Interamericana para Prevenir, Punir e Erradicar a Violência Contra a Mulher, a criação dos Tribunais Internacionais para lidar com os terríveis casos de violência contra a mulher nos conflitos da Antiga lugoslávia e Ruanda, e a conferência seguinte, em Pequim, em 1995, tendo o tema da violência contra a mulher, principalmente no âmbito de conflitos armados, como foco central de debate.

Diferentemente da Convenção para a eliminação de todas as formas de discriminação contra a mulher (CEDAW) de 1979, que resultou em um instrumento juridicamente vinculante, obrigando os Estados a agirem, as convenções da década de 1990 não converteram seus documentos em obrigações de cumprimento estatal, mas são de extrema importância para abrirem precedentes de pressão por parte de grupos da 
sociedade civil. Já as Resoluções do Conselho e Segurança, a partir dos anos 2000 , são os principais instrumentos que constrangem e definem obrigações para os Estados, a fim de desenvolver ações para alcançar as metas propostas de promoção dos direitos das mulheres.

As TANs de mulheres conseguiram alcançar diversos objetivos num tempo curto de 20 anos. De 1975 até os anos 1995, as mulheres foram capazes de colocar uma temática que até então não tinha importância no discurso político como um dos temas principais da agenda internacional, além de expandi-la para escopos maiores como em situações de conflitos armados. A questão da violência, por agregar mais as demandas do Sul e Norte global, conseguiu conciliar e criar um movimento mais global e representativo. A luta contra a violência física ainda é um ponto de convergência, diferentemente de princípios de desigualdade e discriminação que muitas vezes esbarram no relativismo cultural, tal e qual a percepção dos direitos das mulheres como um direito humano que ainda enfrenta desafios que as consideram, muitas vezes, normas do ocidente. Dessa forma, muitas feministas agora pretendem incorporar a violência contra a mulher como uma questão de saúde, que tende a criar mais conscientização e auxiliar no atendimento às vítimas, além de ultrapassar esse debate divergente que a análise de Direitos Humanos até agora promove.

A mulher na sociedade mundial ainda é tida como um ser "inferior" e "frágil". Assim, é perceptível a utilização, durante períodos de guerra, de uma posição dominante tida como masculina e a feminilização do oponente. Dessa forma, as percepções mais básicas, muitas vezes tidas como irrelevantes ou até naturais e biológicas dos gêneros, são refletidas nas mais graves ações durante o nosso dia a dia, dentro de nossas instituições e durante períodos de rompimento com os padrões sociais, como conflitos armados, nas quais essas atitudes se acentuam ainda mais.

Devido à pressão das TANs, a violência contra as mulheres durante um conflito armado é altamente proibida por diversos tratados e normas, tanto internacionais, como consuetudinárias e nacionais. Isto é, o problema não reside mais na falta de diretrizes para promoção do direito das mulheres, mas, sim, na falta de observância dessas normas.

Inexiste vontade política por parte de Estados e de muitas organizações para focar na questão da violência contra as mulheres durante conflitos armados. Isso ocorre devido ao sentimento de impunidade, pela crença de que essa é uma situação decorrente do momento perigoso que se vive, sendo uma consequência da guerra, ou, também, por acreditarem que tenham questões mais importantes para serem verificadas anteriormente.

A violência contra as mulheres durante os conflitos armados é a intensificação da desigualdade enfrentada diariamente por mulheres, em todos os cantos do mundo, em períodos de paz. Dessa forma, é importante que em conjunção com as normas existentes e diretrizes que obrigam os Estados e Organizações a cumprirem essas normas, as concepções mais básicas das dicotomias de gênero e diferenças socialmente criadas entre homens e mulheres sejam desconstruídas entre as pessoas e dentro das instituições.

\section{Referências}

AMNESTY INTERNATIONAL. 70 years on, the "comfort women" speaking out so the truth won't die. Disponível em: https://www.amnesty.org/en/latest/campaigns/2015/09/70-years-oncomfort-women-speak-out-so-the-truth-wont-die/. Acesso em: 14/10/2015.

. Making Rights a Reality: Violence against Women in Armed Conflict. London: Amnesty International Publications, 2005.

BALLESTRIN, Luciana. "Feminismos Subalternos: contribuições, tensões e limites". In: $39^{\circ}$ ENCONTRO ANUAL DA ANPOCS. GT 10: DEMOCRACIA E DESIGUALDADES, 2015. 
BASTICK, Megan; GRIMM, Karin; KUNZ, Rahel. Sexual Violence in Armed Conflict: Global Overview and Implications for the Security Sector. Geneva: Geneva Centre for the Democratic Control of Armed Forces, 2007.

BRASIL. Decreto $n .^{\circ}$ 4388, de 25 de setembro de 2002. Promulga o Estatuto de Roma do Tribunal Penal Internacional. Presidência da República, Casa Civil, Subchefia para Assuntos Jurídicos. Brasília, 2002.

BUNCH, Charlotte. "International Networking for Women's Human Rights". Global Citizen Action. Boulder: Lynne Rienner Publishers, 2001.

COLLOQUIUM ICRC - EUISS. "Report: Women and War: Women and Armed Conflicts and the Issue of Sexual Violence". In: COLLOQUIUM WOMEN AND ARMED CONFLICTS AND THE ISSUE OF SEXUAL VIOLENCE. INTERNATIONAL COMMITTEE OF THE RED CROSS (ICRC) AND THE EUROPEAN UNION INSTITUTE FOR SECURITY STUDIES (EUISS), 2014.

ENLOE, Cynthia. Bananas, Beaches and Bases: Making Feminist Sense of International Politics. California: University of California Press, 2014.

FRIEDMAN, Elisabeth Jay. "Gendering the agenda: the impact of the Transnational women's rights movement at the UN conferences of the 1990s". WOMEN'S STUDIES INTERNATIONAL FORUM, v. 26, n. 4, p. 313-331, 2003.

GOLDSTEIN, Joshua S. War and Gender: How Gender Shapes the War System and Vice Versa. Cambridge: Cambridge University Press, 2001.

KECK, Margaret E.; SIKKINK, Kathryn. Activists beyond Borders: Advocacy Networks in International Politics. New York: Cornell University, 1998.

. Transnational Advocacy Networks in International and regional politics. UNESCO, 1999.

KEOHANE, Robert O. "International Relations Theory: Contributions of a Feminist Standpoint". Millennium - Journal of International Studies, California, Sage Publications, 1989.

MCFARLAND, Joan. "From Feminism to Women's Human Rights: The Best Way Forward?". Atlantis, v. 22, n. $2,1998$.

MOHANTY, Chandra Talpade. "Bajo los ojos de occidente. Academia Feminista y discurso colonial”. In: ___. Descolonizando el Feminismo: teorías y prácticas desde los márgenes. Māidid: Cátedra, 2008.

MONTE, Izadora Xavier do. "O Debate e os Debates: abordagens feministas para as relações internacionais". Revista Estudos Feministas, vol. 21, no. 1, p. 59-80, 2013.

ОКАМОTO, Julia Yuri. "As Mulheres de Conforto na Guerra do Pacífico". Revista de Iniciação Científica de Relações Internacionais, UFPB, v. 1, n. 1, p. 91-108, 2013.

SYLVESTER, Christine. Feminist International Relations: an unfinished journey. Cambridge: Cambridge Studies in International Relations, n. 77, 2002.

TICKNER, J. Ann. Gender in International Relations: feminist perspectives on achieving global security. New York: Columbia University Press, 1992.

Gendering World Politics: Issues and Approaches in the Post-Cold War Era. New York: Columbia University Press, 2001.

UNITED NATIONS INTERNATIONAL CRIMINAL TRIBUNAL FOR RWANDA. The ICTR in Brief. Disponível em: http://www.unictr.org/en/tribunal. Acesso em: 03/1 1/2015.

UNITED NATIONS INTERNATIONAL CRIMINAL TRIBUNAL FOR THE FORMER YUGOSLAVIA. About the ICTY. Disponível em: http://www.icty.org/en/about. Acesso em: 03/1 1/2015.

UNITED NATIONS SECURITY COUNCIL. Resolution 1325/2000, United Nations, 2000.

UNITED NATIONS WOMEN. Beijing + 20: Past, present and Future. The Representation of Women and the United Nations System 1995-2030. United Nations, 2015.

UNITED NATIONS. Declaração e Programa de Ação de Viena, 1993. Disponível em: http:// www.unwomen.org/en. 
A/RES/48/104. General Assembly, 20/12/1993. Disponível em: http://www.un.org/ documents/ga/res/48/a48r104.htm.

. Sexual Violence and Armed Conflicts: United Nations Response. Published to Promote the Goals of Beijing Declaration and the Plataform for Action, 1998.

Stop Rape Now. UN Action against Violence in Conflict. Progress Report 2013-2014.

Disponível em: http://www.stoprapenow.org/uploads/docs/

UN_Action_Progress_Report_2013-2014.pdf.

United to End Violence Against Women. New York: UN Department of Public

Information, 2009. Disponível em: http://www.unwomen.org/en/what-we-do/ending-

violence-against-women/global-norms-andstandards. Acesso em: 07/2015.

. United Nations Fund for Action Against Sexual Violence in Conflict, 2014. Disponível em: http://mptf.undp.org/factsheet/fund/UNAOO.

WARD, Jeanne; MARSH, Mendy. "Sexual Violence against Women and Girls in War and Its Aftermath: realities, responses and required resources". A Briefing Paper. In: SYMPOSIUM ON SEXUAL VIOLENCE IN CONFLICT AND BEYOND. Bruxelas, Bélgica, 23-26 de junho, 2006.

WEBER, Cynthia. "Good Girls, Little Girls, and Bad Girls: Male Paranoia in Robert Keohane's Critique of Feminist International Relations". Millennium - Journal of International Studies, v. 23 , n. 2 , p. 337-349, 1994.

[Recebido em 05/04/2016 e aprovado em 09/09/2016]

\section{Armed Conflicts and the International Agenda: The Women's Matter}

Abstract: Violence against women is not a new debate and women have been organized for over a century to fight for its claims. However, its introduction as an important issue on the international agenda was recent and relied on the efforts of women's groups. Thus, this paper aims to analyze if the movements of women since 1945 with the creation of the United Nations, influenced the incorporation of the issue of violence against women in the international system of human rights protection, especially in times of armed conflict, as well as the compliance of these guidelines by States and international organizations. The argument presented here is that only in the 1990s, with the Transnational Advocacy Networks (TANs) of women and the consideration of women's rights as a fundamental human right, was that the theme received the valuation it deserved on the international agenda. This impact also leaked to the scope of armed conflict where women are the most affected and vulnerable during war time. Thus, several rules were created in order to eliminate gender violence, and it is concluded that the main flaw remains in compliance with these guidelines, both the state and international levels.

Keywords: Violence against Women; Feminism; Human Rights; Armed Conflicts

Iazana Matuella (iazana.matuella@hotmail.com) é graduada em Relações Internacionais pela Universidade Federal de Pelotas com foco na pesquisa sobre gênero e Relações Internacionais. 